\title{
Long-term colonization of the cystic fibrosis lung by Burkholderia cepacia complex bacteria: epidemiology, clonal variation, and genome-wide expression alterations
}

\author{
Carla P. Coutinho ${ }^{1}$, Sandra C. dos Santos ${ }^{1}$, Andreia Madeira ${ }^{1,2}$, Nuno P. Mira ${ }^{1}$, Ana S. Moreira ${ }^{1}$ and \\ Isabel Sá-Correia ${ }^{1,2 *}$ \\ Institute for Biotechnology and Bioengineering, Centre for Biological and Chemical Engineering, Instituto Superior Técnico, Technical University of Lisbon, Lisbon, \\ Portugal \\ ${ }^{2}$ Department of Bioengineering, Instituto Superior Técnico, Technical University of Lisbon, Lisbon, Portugal
}

\section{Edited by:}

Joanna Goldberg, University of

Virginia Health System, USA

Reviewed by:

Jose A. Bengoechea, Fundacion Caubet-CIMERA Illes Balears, Spain

Lisa A. Morici, Tulane University

School of Medicine, USA

*Correspondence:

Isabel Sá-Correia, Institute for Biotechnology and Bioengineering, Centre for Biological and Chemical Engineering, Department of

Bioengineering, Instituto Superior

Técnico, Av. Rovisco Pais, 1049-001

Lisbon, Portugal.

e-mail: isacorreia@ist.utl.pt
Long-term respiratory infections with Burkholderia cepacia complex (Bcc) bacteria in cystic fibrosis (CF) patients generally lead to a more rapid decline in lung function and, in some cases, to a fatal necrotizing pneumonia known as the "cepacia syndrome." Bcc bacteria are ubiquitous in the environment and are recognized as serious opportunistic pathogens that are virtually impossible to eradicate from the CF lung, posing a serious clinical threat. The epidemiological survey of Bcc bacteria involved in respiratory infections at the major Portuguese CF Treatment Center at Santa Maria Hospital, in Lisbon, has been carried out by our research group for the past 16 years, covering over 500 clinical isolates where $B$. cepacia and $B$. cenocepacia are the predominant species, with $B$. stabilis, $B$. contaminans, $B$. dolosa, and $B$. multivorans also represented. The systematic and longitudinal study of this CF population during such an extended period of time represents a unique case-study, comprehending 41 Bcc-infected patients (29 pediatric and 12 adult) of whom around $70 \%$ have been persistently colonized between 7 months and 9 years. During chronic infection, the CF airways represent an evolving ecosystem, with multiple phenotypic variants emerging from the clonal population and becoming established in the patients' airways as the result of genetic adaptation. Understanding the evolutionary mechanisms involved is crucial for an improved therapeutic outcome of chronic infections in CF. This review focuses on our contribution to the understanding of these adaptive mechanisms based on extensive phenotypic, genotypic, and genome-wide expression approaches of selected Bcc clonal variants obtained during long-term colonization of the CF airways.

Keywords: cystic fibrosis, chronic respiratory infection, long-term colonization, Burkholderia cepacia complex, Burkholderia cenocepacia, genome-wide expression, clonal variation

\section{BURKHOLDERIA CEPACIA COMPLEX BACTERIA IN CYSTIC FIBROSIS RESPIRATORY INFECTIONS}

The Burkholderia cepacia complex (Bcc) bacteria are important opportunistic human pathogens, especially in cystic fibrosis $(\mathrm{CF})$ patients (Drevinek and Mahenthiralingam, 2010). CF is an inherited chronic disease, with a median prevalence value of about 0.737 patients per 10,000 in the 27 European Union (EU) countries (Farrell, 2008). CF is characterized by the absence of a functional chloride transporter known as cystic fibrosis transmembrane conductance regulator (CFTR) that is normally present in epithelial cell membranes, resulting in multiple organ system impairment (Sheppard and Welsh, 1999; Ratjen and Döring, 2003; Gadsby et al., 2006). CFTR plays a crucial role in regulating fluid secretion by the airways, intestines, sweat glands, and other epithelial tissues, and the respiratory tract is one of the most profoundly affected systems where the defect in ion transport results in accumulation of highly viscous mucus. The resulting ineffective mucociliary clearance in the lung leads to colonization of the airways with several bacterial pathogens and, ultimately, to respiratory infections that are the major cause of morbidity and mortality in individuals with CF (Ratjen and Döring, 2003).

The large majority of respiratory infections among CF patients are caused by Pseudomonas aeruginosa, while bacteria of the Bcc infect a smaller fraction of these patients (Lyczak et al., 2002; Govan et al., 2007). However, Bcc infections are particularly threatening and feared by CF patients, since they give rise to a highly variable and unpredictable clinical outcome, ranging from asymptomatic carriage to a fulminating septicemia with acute respiratory failure known as "cepacia syndrome" (Jones et al., 2001; Mahenthiralingam et al., 2005). Pulmonary colonization with Bcc is largely associated with a worse prognosis and an increased risk of death; consequently, Bcc-infected patients are frequently excluded from consideration for lung transplantation (Lyczak et al., 2002). Bcc bacteria are often resistant to most clinically used antibiotics (Fux et al., 2005; Leitao et al., 2008). This trait and the ability to develop high-level resistance during antibiotic treatment and to adapt and resist to other adverse environmental conditions severely hinders the effective treatment of Bcc respiratory infections, rendering 
their eradication from the CF lung very difficult if not virtually impossible (Burns, 2007). Although a transient infection of the respiratory tract may occur for some patients, the acquisition of Bcc most typically results in chronic infection. Bcc chronic infections usually involve a single strain; however, prolonged coinfection with two or more distinct strains or species and the replacement of an initial infecting strain with another during the course of chronic infection can also occur (Richau et al., 2000; Cunha et al., 2003, 2007; Yang et al., 2006; Harrison, 2007; LiPuma, 2010). Furthermore, during chronic colonization of the CF airways, microbial pathogens undergo widespread positive selection across the genome (Harrison, 2007). Although recent studies have tried to shed light on the topic of microbial evolution within the CF lung, the focus has been mainly on P. aeruginosa (Smith et al., 2006; Feliziani et al., 2010; Schobert and Tielen, 2010), while equivalent studies on Bcc bacteria remain conspicuously lacking.

\section{A 16-YEAR SYSTEMATIC STUDY OF BURKHOLDERIA CEPACIA COMPLEX RESPIRATORY INFECTIONS IN A PORTUGUESE CYSTIC FIBROSIS CENTER BACKGROUND INFORMATION}

In this review we aim to give a contribution to the understanding of relevant aspects of Bcc bacteria-mediated respiratory infections in CF patients, based on the epidemiological surveys carried out by our research group of a case-study population that has been routinely followed for the past 16 years at the CF Treatment Center of Santa Maria Hospital (HSM), in Lisbon. This CF population comprises a total of 124 patients, of which $58 \%$ are children (up to 18 years old) and $42 \%$ are adults (Figure 1). In the CF pediatric population $54 \%$ are female and $46 \%$ are male, while in the CF adult population $58 \%$ are females and $42 \%$ males. Bcc bacteria have been isolated from 41 of these patients, belonging to both the adult $(n=12)$ and pediatric $(n=29)$ populations. The age at the time of the first Bcc isolation varied between a few months of life and 28 years old, with an estimated mean age of 10 years.

Studies involving the use of $B$. cenocepacia isolates collected from CF patients at HSM were approved by the ethics committee of the Hospital, and the anonymity of the patients is preserved.

\section{PREVALENCE OF DIFFERENT Bcc SPECIES}

The CF subpopulation is represented by a collection of $506 \mathrm{Bcc}$ clinical isolates and clonal variants that were gathered during our 16-year collaboration with the HSM CF Center. This collection includes serial isolates recovered from persistently colonized patients from the early to late stages of infection. According to this routine, sputum samples are obtained from CF patients every 23 months, during periodic consultations to monitor their clinical status, or more often for patients showing clinical deterioration (Cunha et al., 2007). The systematic molecular analysis of the 506 isolates revealed that the most prevalent Bcc species recovered from the sputa of the $41 \mathrm{Bcc}$-infected patients are B. cepacia and B. cenocepacia (Figure 2A).

While $B$. cepacia is not a predominant Bcc species among the CF population characterized worldwide (Mahenthiralingam and Vandamme, 2005), detailed molecular analysis unveiled an exceptionally high incidence of B. cepacia at the HSM CF Center from
2003 to 2005 (Figure 2B), with isolates being retrieved from 11 out of 13 Bcc-infected patients (Cunha et al., 2007). This abnormal prevalence of $B$. cepacia was associated with two B. cepacia clones that were indistinguishable from two strains isolated from contaminated non-sterile saline solutions for nasal application, detected during routine market surveillance by the Portuguese Medicines and Health Products Authority, INFARMED (Cunha et al., 2007). After this contamination was detected, the number of $B$. cepacia isolates identified at HSM gradually declined over the following years, although still remaining significantly high due to persistent colonization of the living patients (Figure 2B). Interestingly, 2005 coincides with a peak in the number of CF patients with newly detected Bcc infections (Figure 2C). Although transmission of Bcc bacteria is considered an important factor in the colonization of CF patients, other primary sources of infection must be taken into account in CF centers where the recommended control measures are followed, as is the case of the CF center at HSM. It is likely that the environment might act as a reservoir for novel Bcc infections (Pallud et al., 2001; LiPuma et al., 2002; Vanlaere et al., 2005), and attention should be given to continuous monitoring of medication for microbial contaminations. Indeed, Bcc bacteria are resistant to multiple antimicrobials and to diverse growth inhibitors that can even be used as carbon sources (Coenye and Vandamme, 2003). Since these bacteria also have minimal nutritional requirements, they are able to grow in aqueous products, including disinfectants (Oie and Kamiya, 1996; Ghazal et al., 2006). Contamination of albuterol and sulbutamol nebulization solutions (Balkhy et al., 2005; Ghazal et al., 2006), nebulizers (Hutchinson et al., 1996), mouthwash (Matrician et al., 2000), nasal sprays (Dolan et al., 2005), and ultrasound gel (Jacobson et al., 2006) have resulted in outbreaks of nosocomial infections by Bcc bacteria. Therefore, the surveillance of unexplained outbreaks of less common pathogens is essential; in particular, those involving poorly represented species, like $B$. cepacia, especially in patients with underlying lung disease and increased risk such as CF patients.

In addition to B. cenocepacia and B. cepacia, four other Bcc species have been isolated from the HSM CF population: $B$. dolosa, B. contaminans, B. stabilis, and B. multivorans (Cunha et al., 2003, 2007, unpublished results; Figures 2A,B,D). Because the taxonomy of Bcc bacteria evolved significantly in the last few years, with the description of eight novel species (Vanlaere et al., 2008, 2009), we have re-examined the species identification of several isolates from our collection. We paid special attention to isolates that were classified as B. cepacia with recA-RFLP profile $\mathrm{K}$ (Cunha et al., 2003 , 2007), since this taxon was recently shown to comprise at least two novel species (Vanlaere et al., 2009), and the multilocus sequence typing (MLST) analysis revealed that several of those isolates now belong to the B. contaminans species. Co-infection with two or three different Bcc species was also observed in nine patients, mainly involving B. cenocepacia and B. cepacia, and in a smaller percentage with $B$. cenocepacia and $B$. contaminans, with B. cenocepacia, B. stabilis, and B. multivorans, or with B. cenocepacia and $B$. dolosa (Figure 2D). Although there is a generalized idea that $B$. cenocepacia is associated with greater morbidity and mortality in CF patients (Speert, 2002; Mahenthiralingam et al., 2005), epidemiological surveys show that all of the species above 


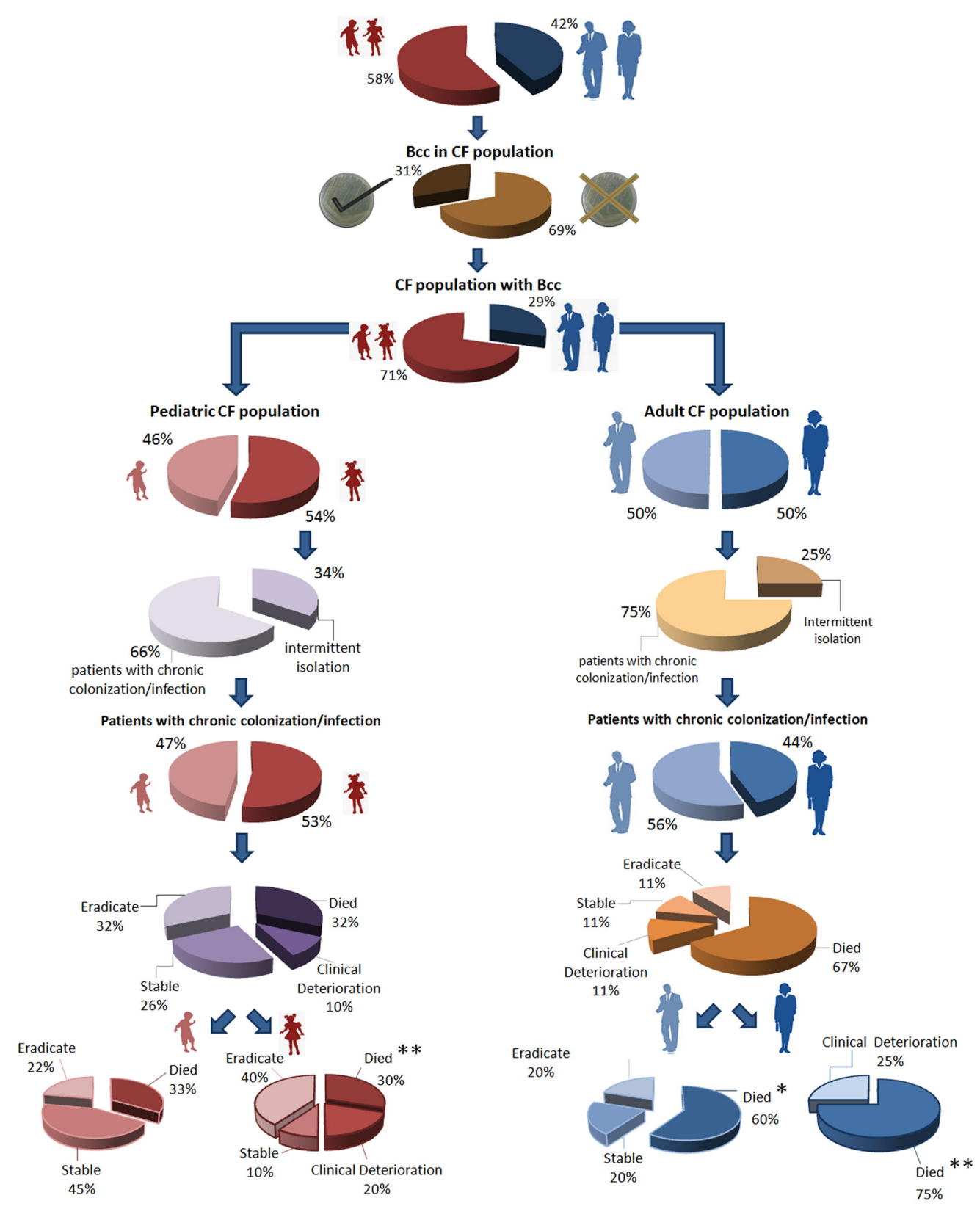

FIGURE 1 | Characterization of the CF subpopulation that has been monitored at the major Portuguese CF Treatment Center at Santa Maria Hospital, in Lisbon, for the past $\mathbf{1 6}$ years. The population was characterized in terms of gender, age, type of colonization, and clinical outcome. Among the deceased patients, at least five had developed the cepacia syndrome at the time of death (each patient marked as $*$ ). Based on the information published in Richau et al. (2000), Cunha et al. (2003, 2007), and on other recent unpublished data. are associated with poor clinical outcome, including the cepacia syndrome, and give rise to chronic and transient infections (Cunha et al., 2003, 2007; Drevinek and Mahenthiralingam, 2010). In fact, it is not clear why strains of different Bcc species differ in their persistence, epidemiology, and pathogenic potential in CF, or why the same strain can be associated with very different clinical outcomes. It probably depends on factors that are inherent to each individual patient, on co-colonization by other pathogens and on other still unidentified factors.

\section{PREVALENCE OF CHRONIC AND TRANSIENT INFECTIONS}

Patients were characterized as persistently colonized with Bcc if at least three positive cultures for these bacteria were recovered during a 6-month period (Cunha et al., 2007). According to this criterion, approximately $68 \%$ of the $41 \mathrm{Bcc}$-infected patients were persistently colonized ( 9 adults and 19 children), for time periods ranging from 7 months to almost 10 years, while the remaining 32\% registered only intermittent isolation (Figure 2E). The majority of the Bcc isolates from our collection are serial isolates 


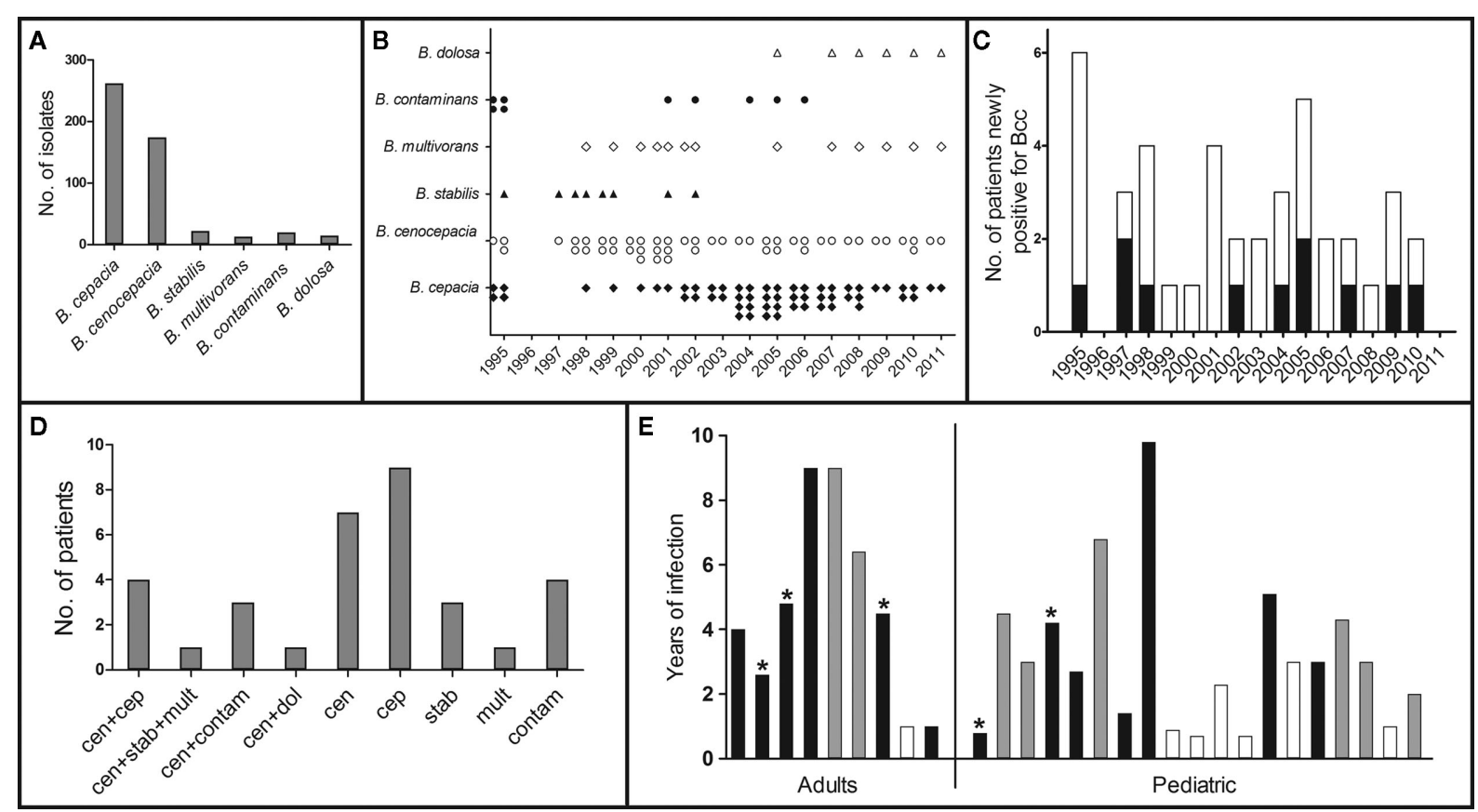

FIGURE 2 | Profiling of the Bcc-infected CF subpopulation. (A) Distribution of the Bcc clinical isolates into the corresponding Bcc species; (B) Chronological distribution of the different Bcc species isolates; (C) Number of patients and date of first Bcc positive isolation (pediatric - white bars and adults - black bars); (D) Number of patients infected with the different species, including co-infection (cen $-B$. cenocepacia; cep - B. cepacia; stab - B. stabilis; mult - B. multivorans; cont - B. contaminans; dol - B. dolosa); (E) Period of duration of chronic infection and clinical outcome (eradication - white bars, death - black bars, * denotes a confirmed cepacia syndrome). Based on the information published in Richau et al. (2000), Cunha et al. (2003, 2007), and on other recent unpublished data. retrieved from these persistently colonized patients, of whom 12 have died during the past 16 years. At least five patients developed a confirmed cepacia syndrome at the time of death, and four were female. When analyzing the clinical outcome of both the adult and pediatric subpopulations of chronically infected patients (Figure 1), it is clear that the worst outcomes lye in the female subpopulation. Within the adult group, all female patients have either died or have a clinically deteriorated status, while $40 \%$ of the male patients have either eradicated the bacteria or are stable. Among the pediatric patients, there is a mixed tendency, with a worse outcome for girls in terms of death or clinical deterioration, but with $50 \%$ of stable or eradicated cases. Interestingly, a female disadvantage regarding a worse prognosis and impaired survival in the course of CF has been documented for years (Kerem et al., 1992; Dodge et al., 1993; FitzSimmons, 1993; Rosenfeld et al., 1997; Fogarty et al., 2000; O’Connor et al., 2003; Barr et al., 2011; TaylorRobinson and Schechter, 2011). This so-called gender gap has been insufficiently explained by a series of risk factors in female patients, including a higher prevalence of CF-related diabetes (Adler et al., 2008), reduced activity levels (Selvadurai et al., 2004), a preponderance for early acquisition of $P$. aeruginosa and Bcc bacteria (Demko et al., 1995; Olesen et al., 2010; Sawicki et al., 2011), and estrogens (Coakley et al., 2008; Zeitlin, 2008; Tam et al., 2011). Most of these factors can be mitigated by the development of modern treatments and standardized intensive care (Verma et al., 2005; Viviani et al., 2011), but the importance of female sex hormones is currently being highlighted by several studies (Coakley et al.,
2008; Zeitlin, 2008; Tam et al., 2011). Estrogen has been shown to aggravate $P$. aeruginosa inflammation in CF mice models (Wang et al., 2010), and in the human lung it has been suggested to augment mucin production (Tam et al., 2011) and impair mucociliary clearance (Coakley et al., 2008; Chotirmall et al., 2010). In fact, 17beta-estradiol was shown to inhibit the CFTR-alternative chloride transporter, especially around ovulation, and this might account for one of the more intrinsic factors in the gender gap of CF (Coakley et al., 2008). Looking back at our pediatric female population, and taking into account that it includes girls up to 18 years old, we observe that all of the nine patients who have eradicated the bacteria or are currently stable are 12 years old or less, an age that is usually before puberty.

\section{ADAPTATION WITHIN THE LUNG OF CF PATIENTS CLONAL PHENOTYPIC VARIATION OF BCC DURING LONG-TERM COLONIZATION OF THE LUNGS OF A CF PATIENT}

During chronic infection of the lung, opportunistic bacterial pathogens within the CF airways evolve in response to stressing selection pressures exerted by the host environment, in particular those resulting from challenges of the immune defenses, antimicrobial therapy, nutrient availability, and oxygen limitation (Harrison, 2007; Hogardt and Heesemann, 2010; Doring et al., 2011). This leads to the emergence of phenotypic variants of the underlying clonal population that exhibit different antimicrobial susceptibility patterns, size of the biofilms formed, and other critical phenotypic differences in the context of bacterial 
pathogenesis (Mahenthiralingam et al., 2002; Cunha et al., 2004, 2007; Smith et al., 2006; Leitao et al., 2008; Coutinho et al., 2011). The occurrence of clonal expansion of B. cenocepacia during longterm colonization of a CF patient was recently shown to occur (Coutinho et al., 2011), but studies on the mechanisms of Bcc bacterial evolution within the $\mathrm{CF}$ airways are still in need. A better understanding of how Bcc bacteria adapt to the CF lung environment while resisting host defense mechanisms and therapeutically administered antibiotics is crucial to deal with these chronic infections. Our group has given a contribution to this field, based on phenotypic and genome-wide expression analyses of serial Bcc clonal variants obtained during infection of CF patients (Moreira et al., 2003; Leitao et al., 2008; Ramos et al., 2010; Coutinho et al., 2011; Madeira et al., 2011; Silva et al., 2011).

The results of a systematic phenotypic assessment of 11 B. cenocepacia sequential isolates (Coutinho et al., 2011), retrieved from the same CF patient sputum during a period of chronic infection, are consistent with the idea that the CF lung can be persistently infected for years by one or more lineages of Bcc (or P. aeruginosa) species with development of clonal expansion (Cunha et al., 2003, 2007; Govan et al., 2007; Drevinek and Mahenthiralingam, 2010). The patient under study (patient J) was chronically colonized with the same strain during three and half years until death with the cepacia syndrome. The clonal nature of the 11 isolates was demonstrated based on recA-RFLP, EcoRI ribopattern (Cunha et al., 2003; Coutinho et al., 2011), and MLST profiling (Cunha et al., 2003; Coutinho et al., 2011). Moreover, the MLST analysis revealed that four of the isolates exhibited a new allelic profile. Although they are not identical clones, all isolates are part of the same clonal Based Upon Related Sequence Types (BURST) group (Coutinho et al., 2011). The phenotypic traits related to bacterial persistence and pathogenicity that were assessed include susceptibility against different classes of antimicrobials, growth efficiency under iron limitation, colony and cell morphology, exopolysaccharide production, size of the biofilms formed, etc. (Coutinho et al., 2011). Interestingly, the more resistant $\mathrm{Bcc}$ clonal variants were isolated following pulmonary exacerbation and aggressive antibiotic therapy (Leitao et al., 2008; Coutinho et al., 2011), suggesting that antibiotic stress drives the emergence of resistant populations of B. cenocepacia isolates.

In general, the properties of the isolate believed to have initiated the infection differ significantly from those exhibited by the isolates obtained during the course of infection (Coutinho et al., 2011). Bacteria are able to grow to high densities in the CF lung in a mucopurulent material that is limited or depleted in oxygen (Worlitzsch et al., 2002), and, until recently, it was generally accepted that $P$. aeruginosa used nitrate-based anaerobic respiration as the primary mode of growth during chronic infections (Yoon et al., 2002). However, recent studies have demonstrated that P. aeruginos $a$ is well adapted to these oxygen-depleted conditions, and that its predominant mode of growth in the CF lung is microaerobic respiration, probably in concert with nitrate respiration (AlvarezOrtega and Harwood, 2007; Hoffman et al., 2010). Very low oxygen availability is currently recognized as an important factor contributing to antibiotic resistance and persistent infections of $P$. aeruginosa in the CF airways (Hoffman et al., 2010; Schobert and Tielen, 2010), but little is known about the underlying molecular mechanisms. However, it appears that the adaptation process in this species predominantly affects metabolic pathways, in particular those involving metabolism of fatty acids, amino acids, and generation of energy (Hoboth et al., 2009). The reduction of membrane fatty acid saturation degree was recently described by our group as an adaptive response of $B$. cenocepacia to growth under severe oxygen-depleted conditions (Coutinho et al., 2011). Notably, the isolates retrieved during the last 10 months of patient J's life evidenced a clear time-dependent decrease of the level of fatty acid saturation that was associated with the depletion of oxygen in the CF lung that accompanies disease progression and the deterioration of lung function (Coutinho et al., 2011). The relevance of the observed reduction in the saturation fatty acid degree for growth of B. cenocepacia bacteria under microaerophilic conditions is currently being investigated in our laboratory, as well as equivalent studies for CF clinical isolates belonging to other Bcc species.

Iron-acquisition mechanisms are key factors for the successful colonization of human infecting bacteria, since the level of free iron within mammals is well below the one required for optimal bacterial growth (Ratledge and Dover, 2000). The importance of iron homeostasis and of its role in determining the success and chronicity of $P$. aeruginosa infections is well documented (Reid et al., 2007, 2009), and there are evidences that Bcc bacteria can alter $P$. aeruginosa physiology and induce several iron-responsive genes through a mechanism that involves iron sequestration by ornibactin (Weaver and Kolter, 2004). As expected, the first B. cenocepacia isolate that was retrieved during long-term infection of patient $\mathrm{J}$ is less suited to grow under iron limitation than most of the subsequent isolates (Coutinho et al., 2011).

Based on the population that was previously characterized at the species and ribopattern levels (Cunha et al., 2003, 2007), we have applied a methodology for the rapid discrimination of Bcc clinical isolates, using Fourier-transform infrared spectroscopy (FTIR) and chemometric analyses (Coutinho et al., 2009). This methodology was found to discriminate between clonal isolates belonging to the same species and exhibiting the same ribopattern (Coutinho et al., 2009, unpublished results). The more prominent differences registered in the FTIR spectral analyses of the clonal variants examined were observed in the $1500-900 \mathrm{~cm}^{-1}$ range, a spectral region that corresponds to polysaccharide, phospholipid, and DNA/RNA molecular vibrations. The whole-bacteria infrared spectral analysis provided by this FTIR-based approach has the potential to be used in Hospitals for the rapid identification of chemical modifications occurring at the bacterial cell surface that may be clinically relevant, including alterations occurring at the level of lipopolysaccharide (LPS) structure, polyhydroxyalkanoates family compounds, lipoproteins, and phospholipids.

\section{APPLICATION OF OMICS APPROACHES TO ELUCIDATE BcC ADAPTIVE STRATEGIES TO THE CF LUNG}

More recently, we have explored OMICS approaches to investigate the adaptive molecular strategies of Bcc bacteria in the CF lung at a molecular systems biology level, based on quantitative proteomics and microarrays analyses (Madeira et al., 2011; Mira et al., 2011). Other OMICS approaches that have been used in 
this context include metabolomics (Behrends et al., 2011; Fang et al., 2011) and the screening of genomic libraries (Moreira et al., 2003; Subsin et al., 2007; Ramos et al., 2010). Metabolomics have been successfully used to study mechanisms of osmotic tolerance in B. cenocepacia (Behrends et al., 2011) and to reconstruct the metabolic network of $B$. cenocepacia J2315, resulting in the identification of new potential therapeutic targets (Fang et al., 2011). The generation of mutant libraries from $B$. cenocepacia and $B$. cepacia strains by random mutagenesis with plasposons led to the identification of the pleiotropic regulator $\mathrm{Pbr}$ as a stress resistance and virulence determinant (Ramos et al., 2010). A similar approach allowed the identification of the gene cluster associated with biosynthesis of the cepacian exopolysaccharide and of the involvement of exopolysaccharide production in the size of the biofilms formed (Moreira et al., 2003; Cunha et al., 2004). Mutant libraries have also been used to identify genes contributing to increased persistence and virulence of B. cenocepacia in the lungs of CF rat models (Hunt et al., 2004; Bernier and Sokol, 2005). An alternative application of genomic libraries described the screening of a random promoter library of B. cenocepacia, which enabled the identification of genes regulated by the cepIR quorum-sensing system (Subsin et al., 2007). The exploitation of OMICS approaches such as phenotypic screens, transcriptomics, proteomics, and metabolomics has been instrumental to get mechanistic insights into the global strategies used by Bcc bacteria to adapt to long-term residence in the stressing environment of the CF lung under antimicrobial therapy. Moreover, the genes and proteins identified represent interesting potential targets for inactivation to enhance antimicrobial activity and to limit colonization by Bcc bacteria.

In this context, the genomic expression of 2 of the $11 \mathrm{~B}$. cenocepacia sequential clonal variants from patient J were compared in our laboratory: IST439, the first isolate that was collected from the patient and is thought to have initiated the infection, and IST4113, an isolate that was recovered almost 3 years later after a period of exacerbated infection and intravenous therapy with gentamicin and ceftazidime (IST4113; Figure 3; Cunha et al., 2003; Coutinho et al., 2011; Madeira et al., 2011; Mira et al., 2011). Among other phenotypic differences, the IST4113 isolate was found to be much more resistant than IST439 to all the tested antibiotics belonging to different classes and having distinct biological targets (Figure 3A; Coutinho et al., 2011; Madeira et al., 2011). The proteome and transcriptome of IST439 and of the highly antibiotic-resistant clonal variant IST4113 were compared using a quantitative proteomics approach based on 2D difference gel electrophoresis (DIGE; Madeira et al., 2011) and custom-made DNA microarrays (Mira et al., 2011 and Drevinek et al., 2008). The cells used for these two genome-wide analyses were cultivated for $24 \mathrm{~h}$ at $37^{\circ} \mathrm{C}$ on the surface of LB solid medium, an experimental setup that mimics the surface-attached bacterial growth expected to occur during chronic colonization of the CF lung. The results of the two studies were complementary, even though the limited protein coverage of the quantitative DIGE-based approach (79 proteins identified) failed to identify a number of relevant gene expression differences that emerged in the transcriptomic analysis, in particular involving functional groups whose identification is difficult to achieve using quantitative proteomics (e.g., transmembrane

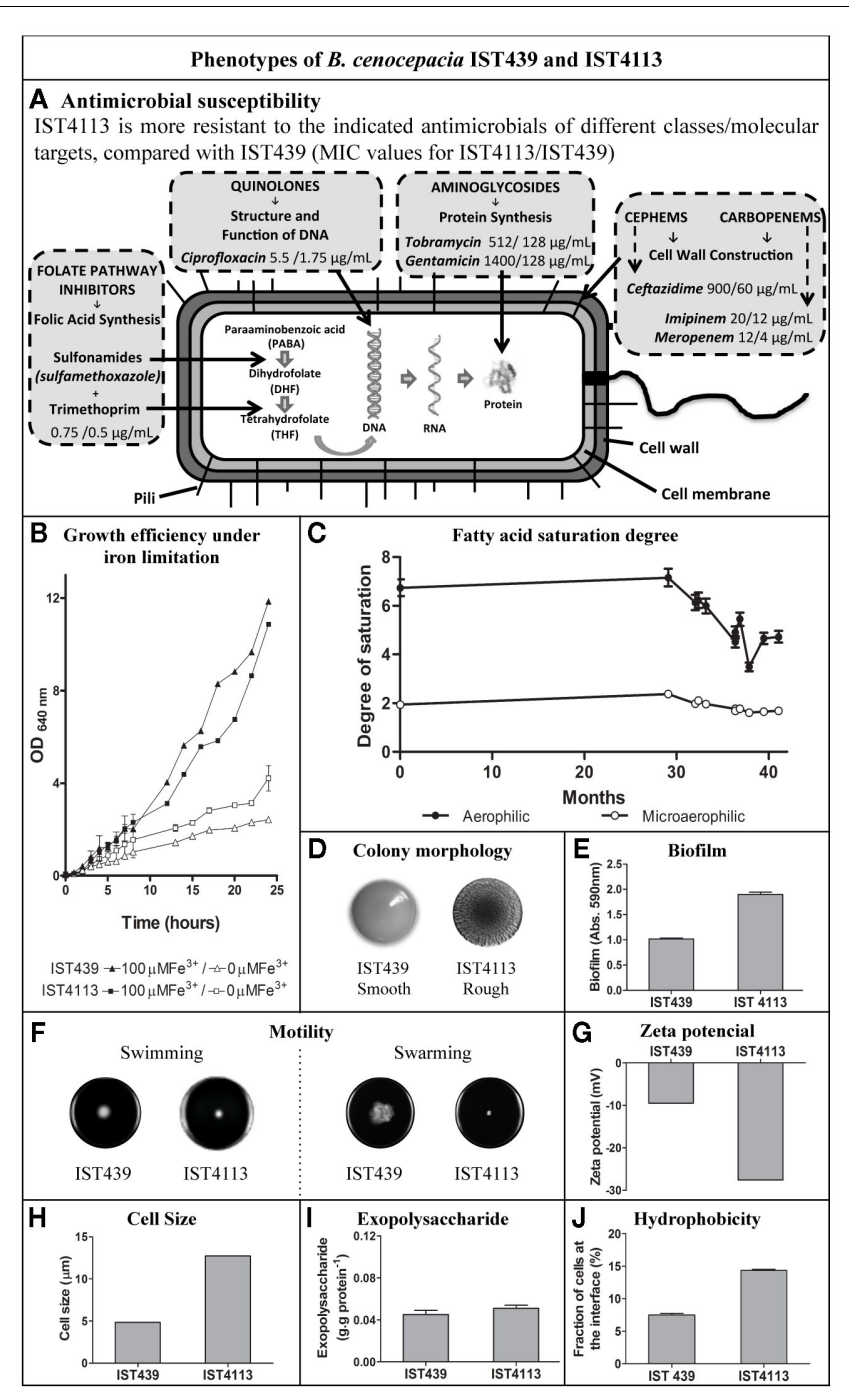

FIGURE 3 | Phenotypic characteristics of the B. cenocepacia clonal variants IST439 and IST4113, retrieved from the same CF patient sputum during long-term residence in the lung and whose genomic expression was compared by quantitative proteomic and transcriptomic analyses. (A) Minimum inhibitory concentration (MIC) values; (B) Growth of IST439 and IST4113 under limited or load iron conditions; (C) Fatty acid saturation of the clonal variants obtained during the 41-months of chronic colonization; (D) Colony morphology; (E) Amount of biofilms formed based on crystal violet method; (F) Swarming and swimming motilities; (G) Zeta potential; (H) Cell size; (I) Exopolysaccharide produced; (J) Fraction of cells at the interface of water and $n$-hexadecane. Based on results from Coutinho et al. (2011) and Madeira et al. (2011).

solute transporters) and low expressed genes/proteins. We identified approximately 1000 genes that are differentially expressed in IST439 and IST4113, reflecting a marked reprogramming of $B$. cenocepacia genomic expression occurring alongside disease progression and clinical deterioration of the patient, similarly to what has been described for P. aeruginosa (Spencer et al., 2003; Hoboth et al., 2009; Yang et al., 2011). In general, the functional classes enriched in the datasets of differently abundant proteins or transcripts in the two isolates coincided, with several genes/proteins 
associated with carbohydrate and amino acid metabolism, translation, iron uptake, nucleotide synthesis, and protein folding being identified as up-regulated in IST4113 (Madeira et al., 2011; Mira et al., 2011).

Several of the observations that emerged from the transcriptomic and proteomic analyses are consistent with the previously carried out phenotypic characterization of the two isolates (Figure 3; Coutinho et al., 2011), and are suggestive of genetic adaptation from isolate IST439 to IST4113. For example, the upregulation of proteins and genes associated with iron binding and transport in IST4113 cells (Madeira et al., 2011; Mira et al., 2011) is in line with the higher efficiency that these cells exhibit to recover iron from an iron-limited environment, when compared to IST439 cells (Figure 3B; Coutinho et al., 2011; Madeira et al., 2011). Notably, a higher capacity to scavenge iron is an adaptive trait that contributes to increase bacterial persistence in the CF lung (Reid et al., 2007, 2009).

The up-regulation of many proteins/genes related with protein synthesis, translation, and protein folding in the IST4113 isolate might also contribute to the higher resistance exhibited by IST4113 against antimicrobials targeting protein synthesis (Figure 3A; Leitao et al., 2008; Coutinho et al., 2011; Madeira et al., 2011), which include the aminoglycosides gentamicin and tobramycin (Jana and Deb, 2006). This marked representation of protein synthesis processes in IST4113 could represent a molecular adaptive strategy to overcome the inhibitory effect of the gentamicin intravenous therapy given to the patient just before the isolation of IST4113. Alterations observed at the level of LPS structure and/or content, cell wall, and outer membrane biogenesis are also consistent with the highly antibiotic-resistant phenotype of IST4113 cells (Figure 3A). Our results suggest that proteins involved in lipid $\mathrm{A}$ and $\mathrm{O}$-antigen formation (two biologically active components of the Bcc LPS) are less expressed in IST4113 (Madeira et al., 2011), which might reflect an adaptive strategy that contributes to protection from the host immune system. In fact, sensing of lipid A has been shown to have a potent pro-inflammatory effect, leading to the onset of immune responses to Bcc infections (De Soyza et al., 2004; Silipo et al., 2007), while O-antigen deficiency has been suggested to contribute to enhanced B. cenocepacia adhesion to bronchial epithelial cells (Saldias et al., 2009). Lower content of the $\mathrm{O}$-antigen has also been associated with a rough colony morphotype (Saldias et al., 2009), an hypothesis that is consistent with the rough colonies formed by IST4113 whereas IST439 cells possess a smooth colony morphotype (Figure 3D; Coutinho et al., 2011; Madeira et al., 2011). Our results also suggest that the content of several outer membrane proteins is lower in IST4113 than in IST439, including several porines that are significantly down-regulated (Madeira et al., 2011; Mira et al., 2011). The outer membrane in Gram-negative bacteria acts as a barrier for resistance to most antimicrobial agents (Nikaido, 2003), and the reduction of outer membrane porines has been described as an important mechanism to maintain the impermeability of the outer membrane and improve antibiotic resistance in Gram-negative bacteria (Moore and Hancock, 1986; Aronoff, 1988; Burns, 2007). At least three of the down-regulated porines in IST4113 are close homologs of porines of other Gram-negative bacteria (including B. cepacia) that have been shown to mediate the entry of antibiotics into the intracellular environment (Moore and Hancock, 1986; Aronoff, 1988; Burns, 2007). IST4113 also possesses higher transcript levels of various drug efflux pumps-encoding genes, which is consistent with the higher active drug export capacity exhibited by these cells when compared to IST439 (Mira et al., 2011). A global overview of the transcriptomic results further shows that alterations related with adaptation to the nutritional microenvironment of the CF lung, in particular at the level of amino acid and energy generation metabolism, is a key feature of the transcriptional reprogramming that characterizes this chronic infection, consistent with the recently established link between metabolism and microbial pathogenicity (Hoffman et al., 2010; Rohmer et al., 2011).

\section{FINAL REMARKS}

For the past 16 years, our group has carried out epidemiological surveys of Bcc bacteria involved in respiratory infections at the HSM CF Treatment Center in Lisbon. This resulted in a systematic and longitudinal characterization of $41 \mathrm{Bcc}$-infected patients, represented by a collection of over 500 clinical isolates retrieved during the patient care routine followed at the hospital. Several of these patients were chronically infected for years, and during that time the bacterial population was subjected to changing selection pressures that led to the development of clonal expansion and emergence of phenotypic variants. To improve our knowledge of the mechanisms behind the underlying genetic adaptation and its impact on bacterial colonization and persistent infection by Bcc bacteria, we have carried out phenotypic and molecular biology analyses of Bcc clinical isolates, as well as genome-wide expression approaches. Genetic adaptation to the stressing conditions of the CF lung, leading to higher antibiotic resistance and bacterial persistence during chronic infection, is suggested by the comparison of the proteomes and transcriptomes of the clonal variants examined. A working model summarizing the most significant findings suggested by our studies and described in this review is proposed in Figure 4. Although the results emerging from these studies provide an important contribution to the current understanding of the adaptive mechanisms employed by $B$. cenocepacia to chronically colonize the lungs of CF patients, it should be emphasized that the isolates examined were randomly selected from a broader heterogeneous colonizing population and thus it is not known how much of the observed responses are representative of the adaptive responses of the entire colonizing population. To elucidate this matter, we are currently extending the OMICS-based studies herein described to other sequential isolates of B. cenocepacia and of other Bcc species obtained from different CF patients. Specific effects exerted by environmental conditions with relevance in the context of CF infections and long-term colonization of the CF lung, such as low oxygen concentrations, are also being examined.

\section{ACKNOWLEDGMENTS}

The contribution, over the last 16 years of epidemiological surveys of Bcc respiratory infections in $\mathrm{CF}$ patients receiving care at Hospital de Santa Maria, in Lisbon, of Luís Lito, Maria José Salgado, José Melo-Cristino, Susana Correia, Celeste Barreto, and Pilar Azevedo, is gratefully acknowledged. The authors would also 


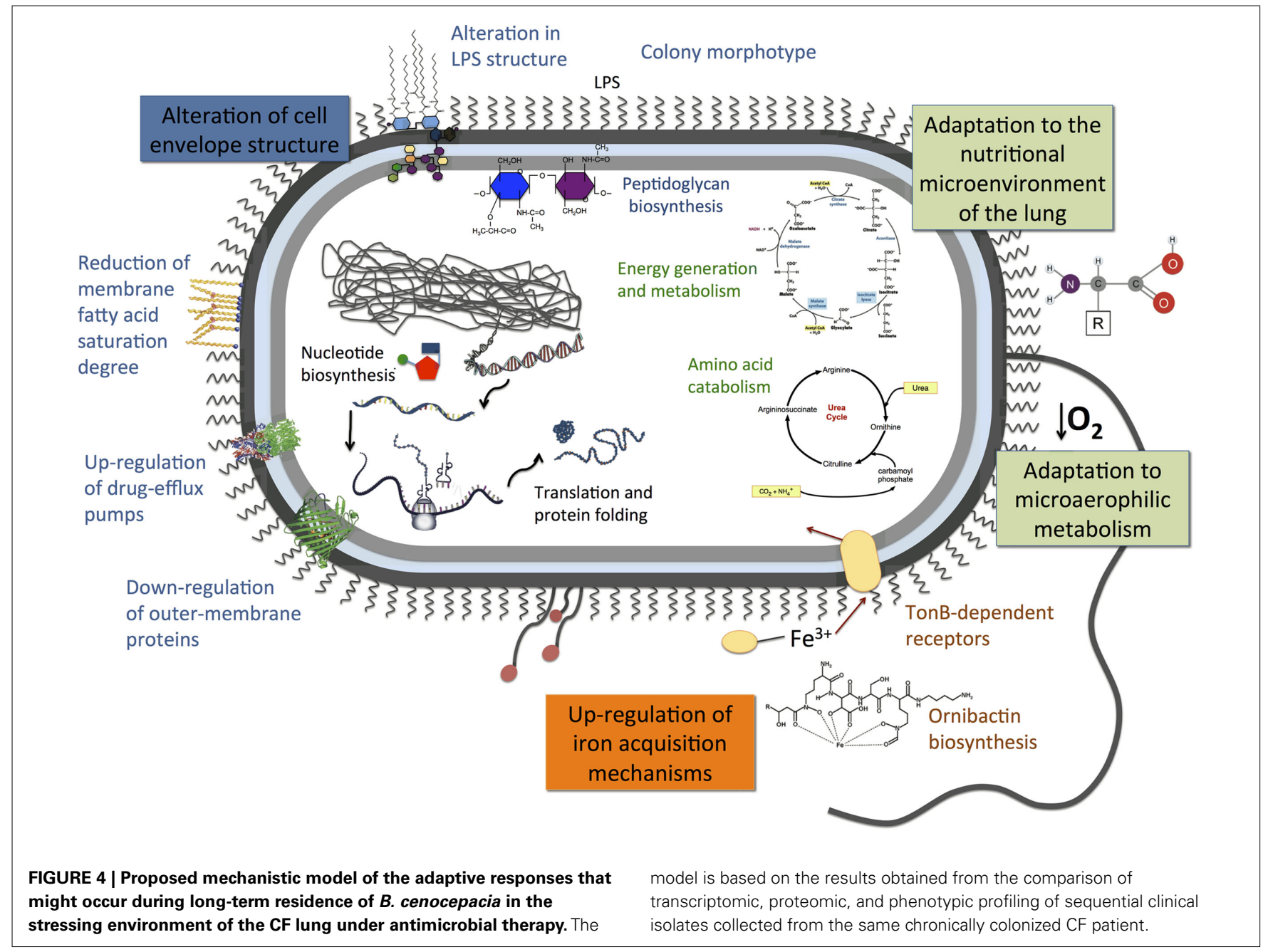

like to acknowledge Andrea Saas and Eshwar Mahenthiralingam, Cardiff School of Biosciences, UK, and Hemant Keller, University of North Carolina, Chapel Hill Center for Bioinformatics, USA, for all the support provided with the execution of microarray experiments and raw data analysis. The work described in this article that was carried out in our laboratory work was funded by "Fundação para a Ciência e a Tecnologia" (FCT, Portugal): contracts PTDC/SAU-MII/69591/2006 and ERAPTG/SAU/0001/2008 - this under the ERA-NET PathoGenoMics

\section{REFERENCES}

Adler, A. I., Shine, B. S., Chamnan, P., Haworth, C. S., and Bilton, D. (2008). Genetic determinants and epidemiology of cystic fibrosis-related diabetes: results from a British cohort of children and adults. Diabetes Care 31, 1789-1794.

Alvarez-Ortega, C., and Harwood, C. S. (2007). Responses of Pseudomonas aeruginosa to low oxygen indicate that growth in the cystic fibrosis lung is by aerobic respiration. Mol. Microbiol. 65, 153-165.
Aronoff, S. C. (1988). Outer membrane permeability in Pseudomonas cepacia: diminished porin content in a beta-lactam-resistant mutant and in resistant cystic fibrosis isolates. Antimicrob. Agents Chemother. 32, 1636-1639.

Balkhy, H. H., Cunningham, G., Francis, C., Almuneef, M. A., Stevens, G., Akkad, N., Elgammal, A., Alassiri, A., Furukawa, E., Chew, F. K., Sobh, M., Daniel, D., Poff, G., and Memish, Z. A. (2005). A National Guard outbreak of Burkholderia cepacia infection and colonization secondary to

ADHRES Signature Project - and post-doctoral and PhD fellowships awarded to Sandra C. dos Santos (SFRH/BPD/75483/2010), Nuno P. Mira (SFRH/BPD/46982/2008), and Andreia Madeira (SFRH/BD/37012/2007). The microarray analysis was sponsored by Cystic Fibrosis Foundation Therapeutics Inc. (CFFT) under the scope of the Burkholderia Array project (contract BA-009-A). This research is also performed under the COST Action BM1003 "Microbial cell surface determinants of virulence as targets for new therapeutics in Cystic Fibrosis."

intrinsic contamination of albuterol nebulization solution. Am. J. Infect. Control 33, 182-188.

Barr, H. L., Britton, J., Smyth, A. R., and Fogarty, A. W. (2011). Association between socioeconomic status, sex, and age at death from cystic fibrosis in England and Wales (1959 to 2008): cross sectional study. BMJ 343. doi: 10.1136/bmj.d4662

Behrends, V., Bundy, J. G., and Williams, H. D. (2011). Differences in strategies to combat osmotic stress in Burkholderia cenocepacia elucidated by NMR-based metabolic profiling. Lett. Appl. Microbiol. 52, 619-625.

Bernier, S. P., and Sokol, P. A. (2005). Use of suppression-subtractive hybridization to identify genes in the Burkholderia cepacia complex that are unique to Burkholderia cenocepacia. J. Bacteriol. 187, 5278-5291.

Burns, J. L. (2007). "Antibiotic resistance of Burkholderia spp.," in Burkholderia: Molecular Microbiology and Genomics, eds T. Coenye and P. Vandamme (Norfolk: Horizon Scientific Press), 81-91. 
Chotirmall, S. H., Greene, C. M., Oglesby, I. K., Thomas, W., O'neill, S. J., Harvey, B. J., and Mcelvaney, N. G. (2010). 17Beta-estradiol inhibits IL-8 in cystic fibrosis by upregulating secretory leucoprotease inhibitor. Am. J. Respir. Crit. Care Med. 182, 62-72.

Coakley, R. D., Sun, H., Clunes, L. A., Rasmussen, J. E., Stackhouse, J. R., Okada, S. F., Fricks, I., Young, S. L., and Tarran, R. (2008). 17Betaestradiol inhibits $\mathrm{Ca} 2+-$-dependent homeostasis of airway surface liquid volume in human cystic fibrosis airway epithelia. J. Clin. Invest. 118, 4025-4035.

Coenye, T., and Vandamme, P. (2003). Diversity and significance of Burkholderia species occupying diverse ecological niches. Environ. Microbiol. 5, 719-729.

Coutinho, C. P., De Carvalho, C. C., Madeira, A., Pinto-De-Oliveira, A., and Sá-Correia, I. (2011). Burkholderia cenocepacia phenotypic clonal variation during a 3.5year colonization in the lungs of a cystic fibrosis patient. Infect. Immun. 79, 2950-2960.

Coutinho, C. P., Sá-Correia, I., and Lopes, J. A. (2009). Use of Fourier transform infrared spectroscopy and chemometrics to discriminate clinical isolates of bacteria of the Burkholderia cepacia complex from different species and ribopatterns. Anal. Bioanal. Chem. 394, 2161-2171.

Cunha, M. V., Leitão, J. H., Mahenthiralingam, E., Vandamme, P., Lito, L., Barreto, C., Salgado, M. J., and Sá-Correia, I. (2003). Molecular analysis of Burkholderia cepacia complex isolates from a Portuguese cystic fibrosis center: a $7-$ year study. J. Clin. Microbiol. 41, 4113-4120.

Cunha, M. V., Pinto-De-Oliveira, A., Meirinhos-Soares, L., Salgado, M. J., Melo-Cristino, J., Correia, S., Barreto, C., and Sá-Correia, I. (2007). Exceptionally high representation of Burkholderia cepacia among $B$. cepacia complex isolates recovered from the major Portuguese Cystic Fibrosis Center. J. Clin. Microbiol.45, 1628-1633.

Cunha, M. V., Sousa, S. A., Leitão, J. H., Moreira, L. M., Videira, P. A., and Sá-Correia, I. (2004). Studies on the involvement of the exopolysaccharide produced by cystic fibrosisassociated isolates of the Burkholderia cepacia complex in biofilm formation and in persistence of respiratory infections. J. Clin. Microbiol. 42, 3052-3058.
De Soyza, A., Ellis, C. D., Khan, C. M., Corris, P. A., and Demarco De Hormaeche, R. (2004). Burkholderia cenocepacia lipopolysaccharide, lipid A, and proinflammatory activity. Am. J. Respir. Crit. Care Med. 170, 70-77.

Demko, C. A., Byard, P. J., and Davis, P. B. (1995). Gender differences in cystic fibrosis: Pseudomonas aeruginosa infection. J. Clin. Epidemiol. 48, 1041-1049.

Dodge, J. A., Morison, S., Lewist, P. A., Coles, E. C., Geddes, D., Russell, G., Jackson, A. D., and Bentley, B. (1993). Cystic fibrosis in the United Kingdom, 1968-1988: incidence, population and survival. Paediatr. Perinat. Epidemiol. 7, 157-166.

Dolan, S., Dowell, E., Valdez, S., Lipuma, J., and James, J. (2005). An outbreak of Burkholderia cepacia complex associated with an intrinsically contaminated nasal spray product. Am. J. Infect. Control 33, e110-e111.

Doring, G., Parameswaran, I. G., and Murphy, T. F. (2011). Differential adaptation of microbial pathogens to airways of patients with cystic fibrosis and chronic obstructive pulmonary disease. FEMS Microbiol. Rev. 35, 124-146.

Drevinek, P., Holden, M. T., Ge, Z., Jones, A. M., Ketchell, I., Gill, R. T., and Mahenthiralingam, E. (2008). Gene expression changes linked to antimicrobial resistance, oxidative stress, iron depletion and retained motility are observed when Burkholderia cenocepacia grows in cystic fibrosis sputum. BMC Infect. Dis. 8, 121. doi:10.1186/1471-2334-8-121

Drevinek, P., and Mahenthiralingam, E. (2010). Burkholderia cenocepacia in cystic fibrosis: epidemiology and molecular mechanisms of virulence. Clin. Microbiol. Infect. 16, 821-830.

Fang, K., Zhao, H., Sun, C., Lam, C. M. C., Chang, S., Zhang, K., Panda, G., Godinho, M., Martins Dos Santos, V. A., and Wang, J. (2011). Exploring the metabolic network of the epidemic pathogen Burkholderia cenocepacia J2315 via genome-scale reconstruction. BMC Syst. Biol. 5, 83. doi:10.1186/1752-0509-5-83

Farrell, P. M. (2008). The prevalence of cystic fibrosis in the European Union. J. Cyst. Fibros. 7, 450-453.

Feliziani, S., Lujan, A. M., Moyano, A. J., Sola, C., Bocco, J. L., Montanaro, P., Canigia, L. F., Argarana, C. E., and Smania, A. M. (2010). Mucoidy, quorum sensing, mismatch repair and antibiotic resistance in Pseudomonas aeruginosa from cystic fibrosis chronic airways infections. PLoS ONE 5, e12669. doi:10.1371/journal.pone.0012669

FitzSimmons, S. C. (1993). The changing epidemiology of cystic fibrosis. $J$. Pediatr. 122, 1-9.

Fogarty, A., Hubbard, R., and Britton, J. (2000). International comparison of median age at death from cystic fibrosis*. Chest 117, 1656-1660.

Fux, C. A., Costerton, J. W., Stewart, P. S., and Stoodley, P. (2005). Survival strategies of infectious biofilms. Trends Microbiol. 13, 34-40.

Gadsby, D. C., Vergani, P., and Csanady, L. (2006). The ABC protein turned chloride channel whose failure causes cystic fibrosis. Nature 440 477-483.

Ghazal, S. S., Al-Mudaimeegh, K., Al Fakihi, E. M., and Asery, A. T. (2006). Outbreak of Burkholderia cepacia bacteremia in immunocompetent children caused by contaminated nebulized sulbutamol in Saudi Arabia. Am. J. Infect. Control 34 394-398.

Govan, J. R., Brown, A. R., and Jones, A. M. (2007). Evolving epidemiology of Pseudomonas aeruginosa and the Burkholderia cepacia complex in cystic fibrosis lung infection. Future Microbiol. 2, 153-164.

Harrison, F. (2007). Microbial ecology of the cystic fibrosis lung. Microbiology 153, 917-923.

Hoboth, C., Hoffmann, R., Eichner, A., Henke, C., Schmoldt, S., Imhof, A., Heesemann, J., and Hogardt, M. (2009). Dynamics of adaptive microevolution of hypermutable Pseudomonas aeruginosa during chronic pulmonary infection in patients with cystic fibrosis. $J$. Infect. Dis. 200, 118-130.

Hoffman, L. R., Richardson, A. R., Houston, L. S., Kulasekara, H. D. Martens-Habbena, W., Klausen, M. Burns, J. L., Stahl, D. A., Hassett, D. J., Fang, F. C., and Miller, S. I. (2010). Nutrient availability as a mechanism for selection of antibiotic tolerant Pseudomonas aeruginosa within the CF airway. PLoS Pathog. 6, e1000712. doi:10.1371/journal.ppat.1000712

Hogardt, M., and Heesemann, J. (2010). Adaptation of Pseudomonas aeruginosa during persistence in the cystic fibrosis lung. Int. J. Med. Microbiol. 300, 557-562

Hunt, T. A., Kooi, C., Sokol, P. A., and Valvano, M. A. (2004). Identification of Burkholderia cenocepacia genes required for bacterial survival in vivo. Infect. Immun. 72, 4010-4022.

Hutchinson, G., Parker, S., Pryor, J., Duncan-Skingle, F., Hoffman, P., Hodson, M., Kaufmann, M., and
Pitt, T. (1996). Home-use nebulizers: a potential primary source of Burkholderia cepacia and other colistinresistant, Gram-negative bacteria in patients with cystic fibrosis. J. Clin. Microbiol. 34, 584-587. [Published erratum appears in J. Clin. Microbiol. 1996 Jun; 34(6):1601].

Jacobson, M., Wray, R. B., Kovach, D. B., Henry, D. B., Speert, D. M., and Matlow, A. M. (2006). Sustained endemicity of Burkholderia cepacia complex in a pediatric institution, associated with contaminated ultrasound gel. Infect. Control Hosp. Epidemiol. 27, 362-366.

Jana, S., and Deb, J. K. (2006). Molecular understanding of aminoglycoside action and resistance. Appl. Microbiol. Biotechnol. 70, 140-150.

Jones, A. M., Dodd, M. E., and Webb, A. K. (2001). Burkholderia cepacia: current clinical issues, environmental controversies and ethical dilemmas. Eur. Respir. J. 17, 295-301.

Kerem, E., Reisman, J., Corey, M., Canny, G. J., and Levison, H. (1992). Prediction of mortality in patients with cystic fibrosis. N. Engl. J. Med. 326, 1187-1191.

Leitão, J. H., Sousa, S. A., Cunha, M. V., Salgado, M. J., Melo-Cristino, J., Barreto, M. C., and Sá-Correia, I. (2008). Variation of the antimicrobial susceptibility profiles of Burkholderia cepacia complex clonal isolates obtained from chronically infected cystic fibrosis patients: a five-year survey in the major Portuguese treatment center. Eur. J. Clin. Microbiol. Infect. Dis. 27, 1101-1111.

LiPuma, J. J. (2010). The changing microbial epidemiology in cystic fibrosis. Clin. Microbiol. Rev. 23 299-323.

LiPuma, J. J., Spilker, T., Coenye, T., and Gonzalez, C. F. (2002). An epidemic Burkholderia cepacia complex strain identified in soil. Lancet 359, 2002-2003.

Lyczak, J. B., Cannon, C. L., and Pier, G. B. (2002). Lung infections associated with cystic fibrosis. Clin. Microbiol. Rev. 15, 194-222.

Madeira, A., Santos, P. M., Coutinho, C. P., Pinto-De-Oliveira, A., and SáCorreia, I. (2011). Quantitative proteomics (2-D DIGE) reveals molecular strategies employed by Burkholderia cenocepacia to adapt to the airways of cystic fibrosis patients under antimicrobial therapy. Proteomics 11, 1313-1328.

Mahenthiralingam, E., Baldwin, A., and Vandamme, P. (2002). Burkholderia cepacia complex infection in patients with cystic fibrosis. J. Clin. Microbiol. 51, 533-538. 
Mahenthiralingam, E., Urban, T. A., and Goldberg, J. B. (2005). The multifarious, multireplicon Burkholderia cepacia complex. Nat. Rev. Microbiol. 3, 144-156.

Mahenthiralingam, E., and Vandamme, P. (2005). Taxonomy and pathogenesis of the Burkholderia cepacia complex. Chron. Respir. Dis. 2, 209-217.

Matrician, L. B. S. N., Ange, G. B. S. N., Burns, S. M. P. H., Fanning, W. L. M. D., Kioski, C. M. P. H., Cage, G. D. M. S., and Komatsu, K. K. M. P. H. (2000). Outbreak of nosocomial Burkholderia cepacia infection and colonization associated with intrinsically contaminated mouthwash. Infect. Control Hosp. Epidemiol. 21, 739-741.

Mira, P. N., Madeira, A., Moreira, A. S., Coutinho, C. P., and SáCorreia, I. (2011). Genomic expression analysis reveals strategies of Burkholderia cenocepacia to adapt cystic fibrosis patients airways and antimicrobial therapy. PlosONE. doi: 10.1371/journal.pone.0028831

Moore, R. A., and Hancock, R. E. (1986). Involvement of outer membrane of Pseudomonas cepacia in aminoglycoside and polymyxin resistance. Antimicrob. Agents Chemother. 30, 923-926.

Moreira, L. M., Videira, P. A., Sousa, S. A., Leitão, J. H., Cunha, M. V., and Sá-Correia, I. (2003). Identification and physical organization of the gene cluster involved in the biosynthesis of Burkholderia cepacia complex exopolysaccharide. Biochem. Biophys. Res. Commun. 312, 323-333.

Nikaido, H. (2003). Molecular basis of bacterial outer membrane permeability revisited. Microbiol. Mol. Biol. Rev. 67, 593-656.

O'Connor, G. T., Quinton, H. B., Kneeland, T., Kahn, R., Lever, T., Maddock, J., Robichaud, P., Detzer, M., and Swartz, D. R. (2003). Median household income and mortality rate in cystic fibrosis. Pediatrics 111, e333-e339.

Oie, S., and Kamiya, A. (1996). Microbial contamination of antiseptics and disinfectants. Am. J. Infect. Control 24, 389-395.

Olesen, H. V., Pressler, T., Hjelte, L., Mared, L., Lindblad, A., Knudsen, P. K., Laerum, B. N., and Johannesson, M. (2010). Gender differences in the Scandinavian cystic fibrosis population. Pediatr. Pulmonol. 45, 959-965.

Pallud, C., Viallard, V., Balandreau, J., Normand, P., and Grundmann, G. (2001). Combined use of a specific probe and PCAT medium to study
Burkholderia in soil. J. Microbiol. Methods 47, 25-34.

Ramos, C. G., Sousa, S. A., Grilo, A. M., Eberl, L., and Leitao, J. H. (2010). The Burkholderia cenocepacia K56-2 pleiotropic regulator $\mathrm{Pbr}$, is required for stress resistance and virulence. Microb. Pathog. 48, 168-177.

Ratjen, F., and Döring, G. (2003). Cystic fibrosis. Lancet 361, 681-689.

Ratledge, C., and Dover, L. G. (2000). Iron metabolism in pathogenic bacteria. Annu. Rev. Microbiol. 54, 881-941.

Reid, D. W., Anderson, G. J., and Lamont, I. L. (2009). Role of lung iron in determining the bacterial and host struggle in cystic fibrosis. Am. J. Physiol. Lung Cell Mol. Physiol. 297, L795-L802.

Reid, D. W., Carroll, V., O'may, C., Champion, A., and Kirov, S. M. (2007). Increased airway iron as a potential factor in the persistence of Pseudomonas aeruginosa infection in cystic fibrosis. Eur. Respir. J. 30, 286-292.

Richau, J. A., Leitão, J. H., Correia, M., Lito, L., Salgado, M. J., Barreto, C., Cescutti, P., and SáCorreia, I. (2000). Molecular typing and exopolysaccharide biosynthesis of Burkholderia cepacia isolates from a Portuguese Cystic Fibrosis Center. J. Clin. Microbiol.38, 1651-1655.

Rohmer, L., Hocquet, D., and Miller, S. I. (2011). Are pathogenic bacteria just looking for food? Metabolism and microbial pathogenesis. Trends Microbiol. 19, 341-348.

Rosenfeld, M., Davis, R., Fitzsimmons, S., Pepe, M., and Ramsey, B. (1997). Gender gap in cystic fibrosis mortality. Am. J. Epidemiol. 145, 794-803.

Saldias, M. S., Ortega, X., and Valvano, M. A. (2009). Burkholderia cenocepacia $\mathrm{O}$ antigen lipopolysaccharide prevents phagocytosis by macrophages and adhesion to epithelial cells. J. Med. Microbiol. 58, 1542-1548.

Sawicki, G. S., Signorovitch, J. E., Zhang, J., Latremouille-Viau, D., Von Wartburg, M., Wu, E. Q., and Shi, L. (2011). Reduced mortality in cystic fibrosis patients treated with tobramycin inhalation solution. Pediatr. Pulmonol.

Schobert, M., and Tielen, P. (2010). Contribution of oxygen-limiting conditions to persistent infection of Pseudomonas aeruginosa. Future Microbiol. 5, 603-621.

Selvadurai, H. C., Blimkie, C. J., Cooper, P. J., Mellis, C. M., and Van Asperen, P. P. (2004). Gender differences in habitual activity in children with cystic fibrosis. Arch. Dis. Child. 89 928-933.

Sheppard, D. N., and Welsh, M. J. (1999). Structure and function of the CFTR chloride channel. Physiol. Rev. 79, S23-S45.

Silipo, A., Molinaro, A., Ierano, T., De Soyza, A., Sturiale, L., Garozzo, D. Aldridge, C., Corris, P. A., Khan, C. M., Lanzetta, R., and Parrilli, M. (2007). The complete structure and pro-inflammatory activity of the lipooligosaccharide of the highly epidemic and virulent Gram-negative bacterium Burkholderia cenocepacia ET-12 (strain J2315). Chemistry (Easton) 13, 3501-3511.

Silva, I. N., Ferreira, A. S., Becker, J. D., Zlosnik, J. E. A., Speert, D. P., He, J., Mil-Homens, D., and Moreira, L. M. (2011). Mucoid morphotype variation of Burkholderia multivorans during chronic cystic fibrosis lung infection is correlated with changes in metabolism, motility, biofilm formation and virulence. Microbiology 157, 3124-3137.

Smith, E. E., Buckley, D. G., Wu, Z. N., Saenphimmachak, C., Hoffman, L. R., D'argenio, D. A., Miller, S. I., Ramsey, B. W., Speert, D. P., Moskowitz, S. M., Burns, J. L., Kaul, R., and Olson, M. V. (2006). Genetic adaptation by Pseudomonas aeruginosa to the airways of cystic fibrosis patients. Proc. Natl. Acad. Sci. U.S.A. 103 , 8487-8492.

Speert, D. P. (2002). Advances in Burkholderia cepacia complex. Paediatr. Respir. Rev. 3, 230-235.

Spencer, D. H., Kas, A., Smith, E. E. Raymond, C. K., Sims, E. H., Hastings, M., Burns, J. L., Kaul, R., and Olson, M. V. (2003). Whole-genome sequence variation among multiple isolates of Pseudomonas aeruginosa. J. Bacteriol. 185, 1316-1325.

Subsin, B., Chambers, C. E., Visser, M. B., and Sokol, P. A. (2007). Identification of genes regulated by the cepIR quorum-sensing system in Burkholderia cenocepacia by highthroughput screening of a random promoter library. J. Bacteriol. 189, 968-979.

Tam, A., Morrish, D., Wadsworth, S., Dorscheid, D., Man, S. F. P., and Sin, D. D. (2011). The role of female hormones on lung function in chronic lung diseases. BMC Womens Health 11, 24. doi:10.1186/1472-6874-11-24

Taylor-Robinson, D., and Schechter, M. S. (2011). Health inequalities and cystic fibrosis. BMJ $343, \mathrm{~d} 4818$.

Vanlaere, E., Baldwin, A., Gevers, D., Henry, D., De Brandt, E., Lipuma, J.
J., Mahenthiralingam, E., Speert, D. P., Dowson, C., and Vandamme, P. (2009). Taxon K, a complex within the Burkholderia cepacia complex, comprises at least two novel species, Burkholderia contaminans sp. nov. and Burkholderia lata sp. nov. Int. J. Syst. Evol. Microbiol. 59, 102-111.

Vanlaere, E., Coenye, T., Samyn, E., Van Den Plas, C., Govan, J., De Baets, F., De Boeck, K., Knoop, C., and Vandamme, P. (2005). A novel strategy for the isolation and identification of environmental Burkholderia cepacia complex bacteria. FEMS Microbiol. Lett. 249, 303-307.

Vanlaere, E., Lipuma, J. J., Baldwin, A., Henry, D., De Brandt, E., Mahenthiralingam, E., Speert, D., Dowson, C., and Vandamme, P. (2008). Burkholderia latens sp. nov., Burkholderia diffusa sp. nov., Burkholderia arboris sp. nov., Burkholderia seminalis sp. nov. and Burkholderia metallica sp. nov., novel species within the Burkholderia cepacia complex. Int. J. Syst. Evol. Microbiol. 58, 1580-1590.

Verma, N., Bush, A., and Buchdahl, R. (2005). Is there still a gender gap in cystic fibrosis? Chest 128, 2824-2834.

Viviani, L., Bossi, A., and Assael, B. M. (2011). Absence of a gender gap in survival. An analysis of the Italian registry for cystic fibrosis in the paediatric age. J. Cyst. Fibros. 10, 313-317.

Wang, Y., Cela, E., Gagnon, S., and Sweezey, N. B. (2010). Estrogen aggravates inflammation in Pseudomonas aeruginosa pneumonia in cystic fibrosis mice. Respir. Res. 11, 166-179.

Weaver, V. B., and Kolter, R. (2004). Burkholderia spp. alter Pseudomonas aeruginosa physiology through iron sequestration. J. Bacteriol. 186, 2376-2384.

Worlitzsch, D., Tarran, R., Ulrich, M., Schwab, U., Cekici, A., Meyer, K. C., Birrer, P., Bellon, G., Berger, J., Weiss, T., Botzenhart, K., Yankaskas, J. R., Randell, S., Boucher, R. C., and Doring, G. (2002). Effects of reduced mucus oxygen concentration in airway Pseudomonas infections of cystic fibrosis patients. J. Clin. Invest. 109, 317-325.

Yang, J. H., Spilker, T., and Lipuma, J. J. (2006). Simultaneous coinfection by multiple strains during Burkholderia cepacia complex infection in cystic fibrosis. Diagn. Microbiol. Infect. Dis. 54, 95-98.

Yang, L., Jelsbak, L., Marvig, R. L., Damkiaer, S., Workman, C. T., Rau, M. H., Hansen, S. K., Folkesson, A., 
Johansen, H. K., Ciofu, O., Hoiby, N., Sommer, M. O., and Molin, S. (2011). Evolutionary dynamics of bacteria in a human host environment. Proc. Natl. Acad. Sci. U.S.A. 108, 7481-7486.

Yoon, S. S., Hennigan, R. F., Hilliard, G. M., Ochsner, U. A., Parvatiyar, K., Kamani, M. C., Allen, H. L., Dekievit, T. R., Gardner, P. R., Schwab, U., Rowe, J. J., Iglewski, B. H., Mcdermott, T. R., Mason, R. P., Wozniak, D. J., Hancock, R. E.,
Parsek, M. R., Noah, T. L., Boucher, R. C., and Hassett, D. J. (2002). Pseudomonas aeruginosa anaerobic respiration in biofilms: relationships to cystic fibrosis pathogenesis. Dev. Cell 3, 593-603.

Zeitlin, P. L. (2008). Cystic fibrosis and estrogens: a perfect storm. J. Clin. Invest. 118, 3841-3844.

Conflict of Interest Statement: The authors declare that the research was conducted in the absence of any commercial or financial relationships that could be construed as a potential conflict of interest.

Received: 09 September 2011; accepted: 15 November 2011; published online: 02 December 2011.

Citation: Coutinho CP, dos Santos SC, Madeira A, Mira NP, Moreira AS and Sá-Correia I (2011) Longterm colonization of the cystic fibrosis lung by Burkholderia cepacia complex bacteria: epidemiology, clonal variation and genome-wide expression alterations. Front. Cell. Inf. Microbio. 1:12. doi: 10.3389/fcimb.2011.00012

Copyright (C) 2011 Coutinho, dos Santos, Madeira, Mira, Moreira and Sá-Correia. This is an open-access article distributed under the terms of the Creative Commons Attribution Non Commercial License, which permits non-commercial use, distribution, and reproduction in other forums, provided the original authors and source are credited. 